\title{
Ecofisiologia e crescimento de Eucalyptus em condição de déficit hídrico ${ }^{1}$
}

\author{
Kristiana Fiorentin dos Santos²; Mauro Valdir Schumacher ${ }^{3}$
}

Resumo: O objetivo dessa revisão bibliográfica é apresentar alguns resultados sobre os efeitos do déficit hídrico no crescimento, na produção e no comportamento ecofisiológico de espécies do gênero Eucalyptus. Para tal será apresentado dados de pesquisas realizadas em diversos países. Desse modo, esta revisão buscará sintetizar resultados científicos sobre os principais aspectos a respeito da eficiência do uso da água, variáveis envolvidas nas trocas gasosas e no status hídrico das plantas (condutância estomática, transpiração, potencial hídrico foliar e fotossíntese), características de crescimento e modificações morfológicas do gênero Eucalyptus sp. Através da literatura consultada, verificou-se que os tratamentos com déficit hídrico afetaram o uso da água, as variáveis envolvidas nas trocas gasosas e no status hídrico das plantas, o crescimento e a morfologia das espécies de Eucalyptus. Portanto, a busca por materiais genéticos tolerantes a seca pode ser relevante para o estabelecimento de povoamentos florestais em áreas com déficit hídrico.

Palavras - chave: Eficiência no uso da água; Status hídrico da planta; Trocas gasosas; Crescimento; Modificações morfológicas.

\section{Ecophysiology and growth of Eucalyptus in drought condition}

\begin{abstract}
The purpose of this literature review is to present some results on the effects of drought on growth, production and ecophysiological behavior of Eucalyptus species. To this will be presented survey data in several countries. Thus, this review will seek to summarize scientific results on the main aspects regarding the efficiency of water use, variables involved in gas exchange and water status of plants (stomatal conductance, transpiration, leaf water potential and photosynthesis) growth characteristics and morphological changes of the genus Eucalyptus sp. Through the literature, it was found, that the treatments with drought affected the use of water, the variables involved in gas exchange and water status of the plants, growth and morphology of Eucalyptus species. Therefore, the search for genetic material tolerant to drought may be relevant to the establishment of forest plantations in areas with water deficit.
\end{abstract}

Keywords: Efficiency in water use; Water status of the plant; Gas exchange; Growth; Morphological changes.

\footnotetext{
${ }^{1}$ Recebido em 22.01.2016 e aceito para publicação como artigo de revisão em 17.08.2016.

${ }^{2}$ Engenheira Florestal, MSc.,Doutoranda do Programa de Pós-graduação em Engenharia Florestal, Universidade Federal de Santa Maria, Santa Maria/RS. Bolsista CAPES. E-mail < kristianafiorentin@gmail.com>.

${ }^{3}$ Engenheiro Florestal, Dr. nat. techn., Professor Titular do Departamento de Ciências Florestais, Universidade Federal de Santa Maria. Email: <mvschumacher@gmail.com>.
} 


\section{Introdução}

O plantio de espécies exóticas aumentou consideravelmente nos últimos anos. No Brasil, os povoamentos com o gênero Eucalyptus ocupam uma área de 5,6 milhões de hectares, destacam-se Minas Gerais, São Paulo e Mato Grosso do Sul, como os estados de maior área plantada (IBÁ, 2016). No entanto, os plantios estão sendo realizados com frequência em regiões propensas a déficits hídricos no solo.

De acordo com Valdés et al. (2013), quando as árvores percebem o déficit hídrico ativam múltiplas respostas para sincronizar seu desenvolvimento e suas atividades moleculares, visando a garantir sua sobrevivência. As plantas respondem as mudanças ambientais alterando diretamente sua fisiologia e sua morfologia, para então sobreviverem ao novo ambiente (TAIZ e ZEIGER, 2014).

A eficiência das plantas em moderar as perdas de água, ao mesmo tempo em que permitem absorção suficiente de $\mathrm{CO}_{2}$ para a fotossíntese, pode ser estimada pela Eficiência do Uso da Água (EUA). Desta forma, estratégias adaptativas para melhorar a EUA são necessárias para atender a demanda de madeira no âmbito global, especialmente em um futuro com o clima mais seco (LACLAU et al., 2016).

Nesse sentido, a gestão bem sucedida dos sistemas florestais requer uma compreensão mais profunda do papel dos traços ecofisiológicos para a adaptação ao déficit de água, pois, eventos de seca ocasionam mudanças significativas na produtividade florestal (MITCHELL e O'GRADY, 2016). Segundo Otto et al. (2013), o entendimento dos fatores que influenciam as respostas fisiológicas dos povoamentos de eucalipto podem ajudar no planejamento, na localização dos plantios e na seleção de genótipos, bem como na escolha do manejo adequado para povoamentos instalados em ambientes com restrições hídricas.

Neste artigo, destacamos o atual estado da arte sobre os efeitos do déficit hídrico no crescimento, na produção e no comportamento ecofisiológico de espécies do gênero Eucalyptus.

\section{Desenvolvimento}

Eficiência do uso da água

O conhecimento sobre a EUA se tornou uma prática agronômica e silvicultural importante para maximizar a produção de plantas em ambientes com déficit hídrico (BLUN, 2005). A preocupação com o uso da água em plantações foi construída sobre uma série de pressupostos que não foram totalmente testados. Muitos fatores têm o potencial de afetar o uso da água em plantios, como as alterações na cobertura florestal, as quais podem ser correlacionadas com outras mudanças ambientais, podendo afetar a transpiração, a precipitação e o escoamento superficial (VANCLAY, 2009).

$\mathrm{O}$ uso da água em uma floresta compreende os processos de transpiração, de evaporação da água no solo e de interceptação da copa (ROBERTS et al., 2015). No entanto, a EUA é sensível as condições ambientais e consequentemente, as alterações ambientais (LACLAU et al., 2016). Em virtude disso, o déficit hídrico do solo afeta o uso da água, pois as árvores usam a água preferencialmente na camada superior (1 metro) do solo, onde estão concentradas as raízes finas responsáveis principalmente pela absorção da água (CALDATO e SCHUMACHER, 2013).

Em estudo realizado por Tatagiba et al. (2008), avaliando as respostas de relações hídricas em Eucalyptus sp. com diferenciada disponibilidade de água no solo, foi observado que os clones que sofreram déficit hídrico registraram os menores valores de EUA, quando comparados com as plantas mantidas irrigadas.

Dados publicados por Hubbard et al. (2010), analisando os efeitos da irrigação em duas plantações de eucaliptos, uma na Aracruz-ES e a outra na Veracel-BA, mostraram que a EUA mensal na Aracruz foi em média $0,73 \mathrm{~kg} \mathrm{C} \mathrm{m}^{-3} \mathrm{e}$ $0,63 \mathrm{~kg} \mathrm{C} \mathrm{m}^{-3}$ em tratamento com déficit hídrico e irrigado. Já a EUA na Veracel foi em média $0,47 \mathrm{~kg} \mathrm{C} \mathrm{m}^{-3} \mathrm{em}$ tratamentos com déficit hídrico e $0,51 \mathrm{~kg} \mathrm{C} \mathrm{m}^{-3}$ em tratamentos irrigados. $\mathrm{O}$ aumento do uso da água nos tratamentos irrigados em ambos os locais foi associado a um 
aumento da área foliar. $\mathrm{O}$ mesmo ocorreu em experimento de Zhu et al. (2015), avaliando uma plantação de Eucalyptus grandis x Eucalyptus urophylla, os quais observaram que o uso da água aumentou linearmente com a área foliar.

Já Silva et al. (2004b), comparando a eficiência do uso da água entre espécies, evidenciaram que o maior crescimento de Eucalyptus citriodora, E. grandis e Brachiaria brizantha foi observado em solos em condições próximo à capacidade de campo $(26 \%)$. No entanto, em condições de déficit hídrico $(20 \%$ de água), a $B$. brizantha apresentou maior eficiência, isto é, proporcionou menor coeficiente transpiratório $(259,8 \mathrm{~g} / \mathrm{g})$ - grama de água por grama de biomassa seca produzida, seguindo-se E. citriodora com 272,2 g/g e $E$. grandis com 284,7 g/g. Mas, quando se trabalhou em condições ótimas de água no solo (26\%), verificou-se esta mesma comparação, com exceção de $E$. citriodora $\operatorname{com} 302,2 \mathrm{~g} / \mathrm{g}$, que passou ser um pouco menos eficiente em relação as condições sob déficit hídrico. Este fato pode explicar o melhor desenvolvimento de $E$. citriodora em condições de pouca disponibilidade de água no solo. Outro estudo, realizado por Martins et al. (2008), avaliando o efeito da deficiência hídrica no solo no desenvolvimento de duas espécies de mudas de eucaliptos observou que os valores de EUA e o total de água consumido para o E. grandis e Eucalyptus saligna foram de 282 e $275 \mathrm{~L} \mathrm{~kg}^{-1}$ de $\mathrm{H}_{2} \mathrm{O}$ de massa seca no tratamento com irrigação e de 241 e $228 \mathrm{~L} \mathrm{~kg}^{-1}$ de $\mathrm{H}_{2} \mathrm{O}$ de massa seca no tratamento sem irrigação. Esses resultados indicam que o E. saligna utiliza mais eficientemente a água do que o E. grandis, por apresentar menor valor de EUA em ambas as épocas estudadas. Segundo Caldato e Schumacher (2013), no Brasil, os principais estudos referentes à eficiência do uso da água estão direcionados principalmente para $E$. grandis na região sudeste, o que se justifica uma vez que a espécie e a região são as de maiores importância e concentração das plantações.

Por outro lado, Otto et al. (2014) avaliando clones de E. grandis e E. urophylla, observaram que árvores com maior tamanho (dominantes) transpiram mais e produzem maior quantidade de madeira por água utilizada. Os estudos apontam que cerca de $40 \%$ do crescimento das árvores dominantes resultaram da maior quantidade de água e $60 \%$ resultaram da maior EUA. A partir disso as árvores dominantes podem alocar uma fração menor de fotossintatos abaixo do solo, deixando uma fração maior de uso no cultivo de hastes, enquanto que as árvores menores consomem quantidades substanciais de água, mas em contrapartida fornecem pouco crescimento.

Em termos de comparação da EUA entre plantações de E. grandis com a floresta ombrófila densa, Almeida e Soares (2003) verificaram que as plantações de E. grandis exercem controle estomático eficiente em condições de baixa disponibilidade de água no solo. As medidas de campo revelaram que as plantações de eucalipto se comparam à Mata Atlântica quanto à evapotranspiração e ao uso de água do solo. Considerando o ciclo de crescimento como um todo (cerca de 7 anos), o eucalipto pode consumir menos água que a mata nativa na região estudada, Aracruz-ES.

Já na Austrália, White et al. (2014) avaliando a EUA em plantações de Eucalyptus globulus observaram que a fertilização nitrogenada pode aumentar a massa de madeira produzida por volume de água utilizada. Ou seja, para o final do verão e início do outono, em 2001, 2002, 2003 e 2004 as parcelas não fertilizadas usaram mais água do que as parcelas adubadas.

Cabe ressaltar que em experimento de Tatagiba et al. (2007a), avaliando dois clones de eucaliptos, mostram que tanto na época seca quanto na chuvosa a eficiência no uso instantâneo de água alcançou os maiores valores às 8 horas. Segundo os autores, nesse horário a demanda evaporativa da atmosfera estava menos estressante sobre as plantas. Por outro lado, a partir desse horário o aumento do déficit de pressão de vapor d'água, da radiação solar, da temperatura e do declínio na umidade relativa do ar contribuíram para a redução na eficiência do uso instantâneo de água para as plantas.

Para Tatagiba et al. (2008), o uso de materiais genéticos de eucalipto capazes de se 
estabelecerem e de se desenvolverem em condições de deficiência hídrica no solo podem ser relevantes para o êxito de um povoamento florestal. Desse modo, a identificação desses genótipos para implantação em condições ambientais com deficiência hídrica no solo é um desafio para as empresas florestais.

Estudos de Vellinni et al. (2008) avaliando o desempenho de 18 genótipos de Eucalyptus spp., em quatro regimes de irrigação (irrigação diária, irrigação a cada dois dias, irrigação a cada quatro dias e irrigação a cada seis dias) concluíram que o regime de irrigação a cada seis dias foi muito severo as plantas e os regimes de irrigação a cada dois e a cada quatro dias constituem condições mais adequadas para a identificação de genótipos promissores para o plantio em locais com restrição hídrica. Segundo Chaves et al. (2009), compreender como as plantas respondem ao déficit hídrico, pode desempenhar um papel importante no desempenho das plantas sob condições de seca, a fim de proteger a vegetação. Portanto, técnicas de melhoramento genético adequado de plantas são ferramentas valiosas para melhorar a eficiência do uso dos recursos (incluindo a água) pelas plantas.

De acordo com Almeida et al. (2007) as empresas madeireiras necessitam melhorar sua compreensão sobre a EUA de plantações florestais, a fim de ajustar suas práticas de gestão para alcançar a sustentabilidade. Dessa forma, estudos ecofisiológicos e hidrológicos de longo prazo parecem ser a melhor maneira de aprimorar continuamente as técnicas de manejo florestal e a otimização do uso da água, aumentando desse modo a produtividade da floresta. Pois, o manejo de plantações, para maximizar o uso da água, também pode minimizar o impacto da produção de madeira sobre os recursos hídricos (WHITE et al., 2014).

Variáveis envolvidas nas trocas gasosas e no status hídrico das plantas

As plantas têm respostas bem definidas a extremos ambientais que as ameaçam. Essas respostas ajudam a tolerar uma diversidade de habitats, como locais com déficit hídrico (TAIZ e ZEIGER, 2014). Quando as plantas percebem o déficit hídrico elas respondem a essas tensões, alterando rapidamente a expressão genética através de alterações fisiológicas e bioquímicas, isso ocorre mesmo sob condições de déficit leve a moderado (CHAVES et al., 2009).

Espécies do gênero Eucalyptus apresentam uma série de respostas fisiológicas e / ou morfológicas, quando confrontados em condições de déficit hídrico (GARAU et al. 2008). Dados de Valdés et al. (2013), publicados na Tasmânia, evidenciaram que o E. globulus exibiu ajustes simultâneos para a aquisição de tolerância à seca, os quais são expressos em níveis fisiológicos e de desenvolvimento molecular.

Cabe ressaltar que em trabalho de Tatagiba et al. (2007b), as variáveis fisiológicas estudadas acompanharam a demanda evaporativa da atmosfera. Segundo os autores, o aumento do déficit de pressão de vapor, da radiação solar incidente, da temperatura do ar e da redução da umidade relativa no período da tarde favoreceu a redução dos valores das trocas gasosas.

Por outro lado, Chaves et al. (2004), com intuito de selecionar clones de Eucalyptos sp. para ambientes com diferenciada disponibilidade de água no solo, avaliou dois ciclos de irrigação. $\mathrm{O}$ autor destacou que os primeiros efeitos visíveis do déficit hídrico foi a paralisação do crescimento, o fechamento dos estômatos e o murchamento das folhas jovens. Por fim, destaca o pesquisador que ao término de cada ciclo a redução do potencial hídrico foi acompanhada por esses efeitos.

Condutância estomática

A capacidade de controlar a abertura estomática permite às plantas responder rapidamente a um ambiente em transformação, para evitar, por exemplo, a perda excessiva de água. A abertura e o fechamento dos estômatos são modulados pela absorção e pela perda de água nas células-guarda, que alteram sua pressão de turgor (TAIZ e ZEIGER, 2014).

À medida que a deficiência hídrica é imposta ocorre redução na condutância estomática 
(CHAVES et al., 2004; SILVA et al., 2004b; PEREIRA et al., 2006; TATAGIBA et al.,2007a; CARNEIRO et al., 2008; TONELLO e TEIXEIRA FILHO, 2013; MUGUNGA et al. 2015). Pois, mantendo os estômatos fechados sob condição de seca as plantas evitam a desidratação (TAIZ e ZEIGER, 2014).

Nesse sentido, Otto et al. (2014), com a finalidade de avaliar a fotossíntese, a condutância estomática e a produtividade de Eucalyptus sp. instalaram dois experimentos, um em área úmida, com precipitação bem distribuída ao longo do ano, e outro em área seca, com precipitação concentrada nos meses quentes do ano. Os autores observaram que na área seca o déficit hídrico foi um fator limitante para a abertura estomática, o que contribuiu para a queda na assimilação de carbono pela fotossíntese. Ao contrário da área úmida, que além de apresentar controle estomático, em função do déficit de pressão de vapor, apresentou maiores valores das taxas fotossintéticas e produtividade. $\mathrm{O}$ mesmo ocorreu em experimento conduzido por Tatagiba et al. (2007a), em que os clones de Eucalyptus sp. submetidos na época seca tiveram condutância estomática reduzida, quando comparados com os clones submetidos na época chuvosa. A maior abertura estomática encontrada durante a época chuvosa pode ter contribuído para os altos valores de fotossíntese encontrados nesta época, devido à ocorrência de um excedente hídrico no solo, disponibilizando água para as plantas.

Dados publicados por Chaves et al. (2004), avaliando cinco clones de Eucalyptus sp., mostram que as plantas submetidas a deficiência hídrica apresentaram condutância estomática de 25,$0 ; 26,8 ; 27,0 ; 26,1 ;$ e $27,3 \mathrm{mmol} \cdot \mathrm{m}^{-2} \cdot \mathrm{s}^{-1}$. Em contrapartida, no tratamento plenamente irrigado a condutância estomática variou de 29,5 a $60,4 \mathrm{mmol} \cdot \mathrm{m}^{-2} \cdot \mathrm{s}^{-1}$. Independentemente do clone, do tratamento de irrigação ou do ciclo de seca, as plantas apresentaram estômatos mais abertos às 9 horas, fechando-se parcialmente às 13 horas e permanecendo assim até às 17 horas. Por outro lado, estudos de Pereira et al. (2006) observaram que próximo às 14 horas foi o período considerado mais crítico, pois apresentou maior resistência estomática em todos os tratamentos.

Segundo Tatagiba et al. (2008), à medida que o déficit hídrico é imposto na época seca, ocorre redução na condutância estomática. Nesse sentido, a interação da deficiência hídrica com outros fatores do ambiente, como altas intensidades luminosas, déficit de pressão de vapor, temperaturas elevadas e baixas umidades do ar podem, também, contribuir para o fechamento parcial dos estômatos.

Transpiração

Alguns autores como Silva et al., 2004a; Pereira et al., 2006; O'grady et al., 2008, Tonello e Teixeira Filho, 2013, constataram que o manejo com déficit hídrico contribui para a redução da transpiração de Eucalyptus sp. em comparação aos manejos irrigados.

Em trabalho de Martins et al. (2008), avaliando o efeito da deficiência hídrica no solo na transpiração de duas espécies de Eucalyptus, observaram que o E. saligna teve maior transpiração e consumiu mais água diariamente que o E. grandis.

A transpiração em clones de Eucalyptus sp. também foi investigada por Tatagiba et al. (2007a), que apontaram ter a espécie na época chuvosa uma maior transpiração em relação à época seca. Desse modo, na época chuvosa os dois clones estudados apresentaram como valores de transpiração cerca de 48,57 \% e 31,44 $\%$, maiores aos encontrados durante a época seca. Esse fato pode ser explicado pela ocorrência do excedente hídrico, disponibilizando considerável quantidade de água no solo na época chuvosa, enquanto na época seca não havia disponibilidade suficiente de água no solo para os clones manterem altas taxas de transpiração.

Em experimento conduzido por Chaves et al. (2004), avaliando cinco clones em cinco ciclos sucessivos de seca foi constatado que no primeiro ciclo de seca avaliado, as plantas plenamente irrigadas apresentaram maior transpiração, em comparação com aquelas sob deficiência hídrica. O mesmo ocorreu em 
trabalho de Hubbard, et al. (2010), onde a transpiração anual foi menor em área de déficit hídrico do que em tratamentos irrigados. Neste experimento, o aumento nas taxas de transpiração em tratamentos irrigados foi associado ao maior índice de área foliar.

Na Espanha, Pita e Pardos (2001), com intuito de avaliar mudanças nos parâmetros da transpiração de mudas de Eucalyptus sp., conduziram experimento em casa de vegetação, no qual avaliaram três tratamentos, sendo eles, controle (30\% peso seco), déficit 1 ( $9,5 \%$ peso seco) e déficit $2(8,6 \%$ peso seco). Os autores observaram que aos 62 e 89 dias de condução do experimento as taxas de transpiração de plantas no tratamento controle foram de 3,3 e 3,5 vezes superiores aos tratamentos déficit 1 e 2, respectivamente.

Em estudo de Pereira et al. (2006), também realizado em casa de vegetação, porém na cidade de Botucatu-SP, os autores observaram que a transpiração ocorreu de acordo com as horas do dia, ou seja, nos horários mais quentes, por volta do meio dia, as plantas tiveram maiores perdas de água. Já em trabalho de Tonello e Teixeira Filho (2013), conduzido na cidade de CampinasSP, foi observado que os maiores valores de transpiração ocorreram no início da manhã, com declínio no decorrer do dia, e em alguns casos, elevou-se ao final do período solar.

Outro estudo realizado por Tatagiba et al. (2007b), evidenciaram que o déficit pressão de

vapor, a temperatura e a umidade relativa do ar afetaram, significativamente a transpiração dos dois clones avaliados, sendo este efeito pronunciado tanto na época seca quanto na chuvosa.

\section{Potencial hídrico foliar}

O potencial hídrico foliar reflete as condições da dinâmica do processo do transporte no sistema solo-água-planta-atmosfera, constituindo o principal componente, responsável pelo fluxo de água na planta (PEREIRA et al., 2006). O potencial hídrico é comumente utilizado como uma medida do status hídrico de uma planta, o qual é dependente do conteúdo de umidade do solo, da capacidade de absorção de água pelas raízes e da condutividade hidráulica de tecidos das raízes e das partes aéreas. Quando o solo está saturado (capacidade de campo), o potencial hídrico do solo pode aproximar-se de zero. Contudo, quando o solo está seco, seu potencial hídrico pode ficar abaixo de $-1,5 \mathrm{MPa}$ e nesse ponto ocorre a murcha permanente (TAIZ e ZEIGER, 2014).

Dados publicados por Chaves et al. (2004), mostraram que as plantas submetidas ao déficit hídrico apresentaram queda no potencial hídrico foliar ao final dos ciclos de seca, variando de $0,8 \mathrm{MPa}$ a $-1,98 \mathrm{MPa}$, nas plantas submetidas à deficiência hídrica, enquanto nas plantas plenamente irrigadas o potencial hídrico foliar variou de -0,25 a -0,35 MPa. Já em experimento de Tatagiba et al. (2007a), o potencial de água das folhas foi reduzido em cerca de 55,42\% e $62,42 \%$ para os mesmos clones durante a época seca. De acordo com Taiz e Zeiger (2014), o decréscimo do teor de água no solo diminui o potencial hídrico na folha, onde suas células não se encontram mais túrgidas, contribuindo para diminuição da condutância estomática e promovendo o fechamento parcial ou total dos estômatos.

Em trabalho de Tatagiba et al. (2007b) foi constatado que na época chuvosa os clones apresentaram maiores valores de potencial hídrico foliar antemanhã, em comparação aos valores encontrados na época seca. Nesse sentido, Pereira et al. (2006) observaram que durante os períodos mais quentes do dia foram obtidos os menores potenciais, devido a resistência difusiva dos estômatos.

Segundo Taiz e Zeiger (2014), a desidratação do solo também aumenta a concentração salina na solução do solo, resultando em um abaixamento do potencial hídrico e determinando o estresse osmótico e os efeitos iônicos específicos.

\section{Fotossíntese}

A obtenção de dados sobre a capacidade fotossintética das plantas é uma importante 
ferramenta para modelos baseados em processos que necessitam de informações fisiológicas para a predição do crescimento e uso da água de diferentes genótipos (OTTO et al., 2013). De acordo com Chaves et al. (2009), os efeitos do déficit hídrico sobre a fotossíntese podem ser diretos, como as limitações de difusão (através dos estômatos e dos mesófilos, e as alterações no metabolismo fotossintético) ou indiretos, como o estresse oxidativo decorrente da superposição de vários estresses.

Vários pesquisadores constataram que em condições de seca a fotossíntese normalmente diminui, o que provavelmente se deve ao fechamento parcial dos estômatos (TATAGIBA et al., 2007a; TATAGIBA et al., 2007b; TATAGIBA et al., 2009; OTTO et al., 2013).

Nesse sentido, Tatagiba et al. (2007b) avaliando as variações diurnas e sazonais das trocas gasosas de dois clones de Eucalyptus sp. observaram aumentos nas taxas fotossintéticas de $44,52 \%$ e $54,26 \%$ na época chuvosa em relação à época seca, os quais podem ser atribuídos à maior disponibilidade de água para as plantas. $\mathrm{O}$ mesmo ocorreu em experimento de Tatagiba, et al. (2007a), avaliando a resposta de clones de Eucalyptus urograndis. Os autores observaram que na época seca a fotossíntese foi reduzida em relação à época chuvosa, em todos os horários ao longo do dia, devido à ocorrência do déficit hídrico no solo. Às 8 horas durante a época seca os clones apresentaram máxima assimilação de $\mathrm{CO}_{2}$, com $17,12 \mathrm{~mol} \cdot \mathrm{m}^{-2} \cdot \mathrm{s}^{-1}$ para o clone 1 e $21,14 \mathrm{~mol} \cdot \mathrm{m}^{-2} \cdot \mathrm{s}^{-1}$ para o clone 2, reduzindo-se a partir deste horário até $\mathrm{o}$ entardecer. $\mathrm{Na}$ época chuvosa os clones 1 e 2 apresentaram maiores valores das taxas fotossintéticas também às 8 horas com 23,90 e 22,97 mol. $\mathrm{m}^{-2} \cdot \mathrm{s}^{-1}$.

Dados publicados por Otto et al. (2013), indicam que a taxa fotossintética máxima atingida pelos quatro clones de Eucalyptus avaliados na área úmida variou de 12,5 a 16,4 $\mu \mathrm{mol} . \mathrm{m}^{-2} \cdot \mathrm{s}^{-1}$. Na área seca, a taxa fotossintética máxima variou de 1,2 a $3,4 \mu \mathrm{mol} \cdot \mathrm{m}^{-2} \cdot \mathrm{s}^{-1}$. Observando a relação linear direta entre a fotossíntese média diária e a produtividade dos clones, os autores evidenciaram que a taxa fotossintética foi um dos fatores responsáveis pela maior produtividade da área úmida. $\mathrm{O}$ mesmo ocorreu em experimento de Tatagiba et al. (2008), onde o maior valor de fotossíntese foi encontrado no manejo hídrico irrigado, com $12,00 \mu \mathrm{mol} . \mathrm{m}^{-2} \cdot \mathrm{s}^{-1}$, às $10 \mu$ horas, enquanto o menor valor foi verificado no manejo hídrico de déficit, no mesmo horário, com $1,19 \mu \mathrm{mol} . \mathrm{m}^{-2} . \mathrm{s}^{-}$ 1 .

Características de crescimento em área com déficit hídrico

No momento que as células vegetais sofrem déficit hídrico ocorre desidratação celular, a qual afeta adversamente processos fisiológicos básicos, como a redução no turgor, no volume celular, na extensibilidade da parede, reduzindo consequentemente o crescimento da planta (TAIZ e ZEIGER, 2014). Nesse sentido, Stape et al. (2010) estudando a influência da água e dos nutrientes na produção de madeira em oito locais do Brasil, observaram que o tratamento sem adubação e sem irrigação teve uma redução de $28 \%$ na média de Incremento Médio Anual (IMA) em relação ao tratamento inicial. Sendo a resposta à irrigação muito maior do que a fertilização (comparando todos os tratamentos irrigados e não irrigados), com IMA aumentando a uma média de $30 \%$. O mesmo autor observou que a taxa de crescimento nos tratamentos irrigados também foi menor durante a estação seca em relação à estação chuvosa, com a diminuição de $19 \%$. O crescimento nas parcelas não irrigadas na estação seca foi $27 \%$ menor do que o crescimento na estação chuvosa, refletindo os efeitos combinados de pouca luz recebida e maior déficit hídrico. Semelhante processo aconteceu em estudo de Ryan et al. (2010), em que o aumento da oferta de água desencadeou maior produção de madeira, em todos os locais estudados (Aracruz-ES, Internacional Paper-SP, Suzano-BA e Veracel-BA).

Por outro lado, Silva et al. (2004b) avaliando o crescimento de E. citriodora e E. grandis, cultivados em solos com três teores de água, associados ou não com Brachiaria brizantha, observaram que o E. citriodora e o E. grandis 
alcançaram os maiores valores de Incremento Médio Anual (IMA) em condições ótimas de água, enquanto que os menores IMA foram registrados sob condições de déficit hídrico. Sendo que nesse teor de água houve menor produção de biomassa seca para as duas espécies de Eucalyptus avaliadas. Já, Silva et al. (2004a) observaram uma redução de cerca de $46 \%$ da média total da biomassa em plantas jovens de Eucalyptus sp. cultivadas quando a água fornecido para os vasos foi de apenas $50 \%$ do uso de água da planta.

Outro estudo realizado por Vellini et al. (2008), constatou que quando a disponibilidade hídrica diminuiu para as plantas o crescimento em altura foi proporcionalmente menos afetado que o crescimento em diâmetro. Já, em experimentos de Tatagiba et al. (2009) e Pereira et al. (2006) no tratamento com déficit hídrico também ocorreu redução no diâmetro dos clones. A altura das plantas apresentou redução com o déficit hídrico no substrato quando comparado com o manejo sem déficit, sendo que, os clones submetidos aos 100 dias de déficit hídrico, foram os mais afetados, com redução em altura variando de $26 \%$ a $46 \%$ (PEREIRA et al., 2006).

Martins et al. (2008), avaliando a resposta da deficiência hídrica no E. saligna e E. grandis, em duas épocas de semeadura (primavera e outono), observaram que os valores de altura, diâmetro e número de folhas na haste principal, começaram a ser afetadas imediatamente após o início da deficiência hídrica. Na primavera e no outono, o E. saligna demorou, respectivamente, dois e cinco dias mais do que o E. grandis para apresentar os sintomas de deficiência hídrica nas variáveis de crescimento e desenvolvimento, indicando que E. saligna é mais tolerante à deficiência hídrica do que E. grandis. Já Ferraz (2012), simulando uma condição de aproximadamente $50 \%$ de interceptação da precipitação pluviométrica para $E$. grandis e $E$. urophylla, também observou comprometimento no crescimento, avaliado pela altura da planta e pelo diâmetro à altura do peito.

Em floresta tropical, Chagas et al. (2012) analisando os efeitos da redução da precipitação pluvial observou que a redução da chuva sobre a floresta afetou todos os parâmetros de crescimento das árvores, cuja principal evidência é de que o efeito da exclusão de chuva provoca redução da área basal florestal, em especial daquelas com diâmetro a altura de peito maior que $10 \mathrm{~cm}$. Os resultados também indicam que o aumento na taxa de mortalidade das árvores e a consequente perda de biomassa vegetal foram maiores na área com exclusão de chuva do que nas florestas submetidas as condições naturais do clima.

\section{Modificações morfológicas}

Em plantas de crescimento indeterminado déficit hídrico não limita apenas o tamanho foliar, mas também o número de folhas, pois ele diminui o número e a taxa de crescimento das ramificações. $\mathrm{O}$ crescimento do caule tem sido menos estudando do que a expansão foliar, mas o processo de crescimento dele provavelmente é afetado pelas mesmas condições que limitam o crescimento foliar durante períodos de baixa disponibilidade de água (TAIZ e ZEIGER, 2014).

Uma diminuição na elasticidade do tecido da folha pode ser uma adaptação importante para manter a absorção de água, quando este recurso se esgota no solo. Pois, a mudança no potencial da água para uma dada mudança no teor relativo de água é maior para as plantas com uma elasticidade elevada do que para plantas com uma baixa elasticidade (PITA e PARDOS, 2001; BLUN, 2005).

Alguns pesquisadores, como Pita e Pardos (2001), Chaves et al. (2004), Silva et al. (2004a), Tatagiba et al. (2009), Pereira et al. (2006), Lima (2015) e Mugunga et al. (2015) comparando áreas com e sem déficit hídrico observaram que em áreas com déficit hídrico ocorreu redução considerada na área foliar. No entanto, com uma diminuição na área foliar a planta irá transpirar menos, conservando efetivamente um suprimento hídrico limitado no solo por um período mais longo (TAIZ e ZEIGER, 2014).

De acordo com Maseda e Fernández (2016), o déficit hídrico modifica a alocação de 
biomassa aérea e radicular da planta. Nesse sentido, dados de Pita e Pardos (2001) publicados no sudoeste da Espanha constataram que em resposta a seca a área foliar e o peso seco total de clones de E. globulus foram reduzidos em $56 \%$ e $36 \%$. Sendo que o tamanho médio das folhas das plantas controle, em que não ocorreu déficit hídrico foi 1,6 vezes maior do que em plantas estressadas. O mesmo ocorreu em trabalho de Tatagiba et al. (2009), em que evidenciaram uma redução na área foliar das plantas, variando de $52 \%$ a $84 \%$ nas plantas mantidas sob déficit hídrico. A redução da área foliar nas plantas sob déficit hídrico prolongado se deu tanto pela abscisão foliar quanto pela diminuição do tamanho das folhas. Em determinadas plantas o déficit hídrico não limitou apenas o seu tamanho, mas também o número de folhas, pois houve uma diminuição do número e na taxa de crescimento dos ramos. Silva et al. (2004a), também observaram uma redução na área foliar no tratamento com déficit hídrico, sendo esta diminuição de $63 \%$ na área total da folha, quando a água fornecida para os vasos foi de apenas $50 \%$ do uso de água da planta.

Em Buenos Aires, os pesquisadores Maseda e Fernándes (2016) avaliando o crescimento de mudas de seis procedências de Eucalyptus em três regimes hídricos (100\% (controle); $72 \%$ (seca moderada) e $51 \%$ (seca severa) da capacidade de campo) observaram que para todas as procedências a biomassa total e a área foliar foram reduzidas quando a intensidade das secas aumentou. Do mesmo modo, em estudo realizado por Chaves et al. (2004) foi observado que ao final dos cinco ciclos de seca as plantas que foram submetidas à deficiência hídrica apresentaram área foliar menor do que as do tratamento plenamente irrigado, em razão da abscisão foliar provocada pelo déficit hídrico. Segundo Taiz e Zeiger (2014), os processos dependentes do turgor, como expansão foliar e o alongamento das raízes, são os mais sensíveis ao déficit hídrico.

No entanto, quando a água para a parte aérea se torna limitante a expansão foliar é reduzida antes que a atividade fotossintética seja afetada.
A inibição da expansão foliar reduz o consumo de carbono e de energia, e uma maior proporção de assimilados da planta pode ser alocada para o sistema subterrâneo, onde podem sustentar continuamente o crescimento de raízes. Essa mudança na arquitetura das raízes pode ser considerada uma linha de defesa contra a dessecação (TAIZ e ZEIGER, 2014).

De acordo com Blun (2005), quando todos os requisitos são efetivamente fornecidos as plantas não precisam de uma grande massa de raízes. Pois, num tal sistema, um grande potencial de raízes é um desperdício de matéria seca. Já, em condições de déficit hídrico, um alto crescimento de raízes é necessário para garantir captação de recursos em condições irregulares. Segundo Santos e Carlesso (1998), o volume de solo explorado e o contato íntimo entre a superfície das raízes e o solo são essenciais para a absorção efetiva da água pelas raízes. Sendo que o contato é maximizado pela emissão dos pelos radiculares, com consequente aumento na área superficial e na capacidade de absorção de água. Além disso, os pesquisadores apontam que o déficit hídrico estimula a expansão do sistema radicular para zonas mais profundas e úmidas do perfil do solo.

Moroni et al. (2003) realizaram pesquisa na Tasmânia comparando a distribuição de raízes em um tratamento irrigado e outro submetido a ciclos de déficit hídrico. Os autores evidenciaram que o desenvolvimento das raízes de E. globulus e Eucalyptus nitens, ocorria em maiores quantidades no tratamento com déficit hídrico, comparando ao tratamento irrigado. $\mathrm{O}$ fornecimento de água por meio da irrigação na superfície do solo reduziu o desenvolvimento radicular e sua exploração no perfil do solo em profundidade. Isto sugere que $o$ desenvolvimento da raiz adicional, em plantações irrigadas, pode ser estimulado através da redução da carga de irrigação durante o ciclo de crescimento.

Já, Matos et al. (2016) conduziram um experimento em casa de vegetação com mudas de Eucalyptus urocan (cruzamento entre $E$. urophylla $\mathrm{x}$ E. camaldulensis), com cinco tratamentos (plantas irrigadas diariamente com 
água correspondente a 25, 50, 75, 100 e 125\% da evapotranspiração diária). Os autores observaram que sob condição de déficit hídrico o E. urocan mostrou significativo investimento no sistema radicular.

Por outro lado, Silva et al. (2004a) avaliando a resposta do déficit hídrico em dois clones de $E$. globulus, sendo um tolerante e outro sensível à seca, observaram que sob condições de seca o clone tolerante à seca tinha visivelmente maior comprimento de raiz e a taxa de expansão de novas folhas do que as plantas sensíveis a seca.

Já, em trabalho conduzido por Valdés et al. (2013), na Austrália, as plantas tolerantes à seca mostraram abscisão parcial e um sistema radicular superando altos níveis de hormônios relacionados ao déficit hídrico e à acumulação de proteínas relacionadas à tolerância de estresse abiótico.

\section{Considerações finais}

Em todos os trabalhos observados os tratamentos com déficit hídrico afetaram o uso da água, as variáveis envolvidas nas trocas gasosas e no status hídrico das plantas (condutância estomática, transpiração, potencial hídrico foliar e fotossíntese), o crescimento e a morfologia das espécies de Eucalyptus.

As consequências do déficit hídrico em plantios do gênero Eucalyptus sp. são variáveis, dependendo da espécie, do clima e do manejo adotado.

A busca por materiais genéticos tolerantes a seca é um desafio para empresas florestais, podendo ser relevante para o sucesso de povoamentos florestais em áreas com déficit hídrico.

\section{Referências bibliográficas}

ALMEIDA, A.C.; SOARES, J.V. Comparação entre uso de água em plantações de Eucalyptus grandis e floresta ombrófila densa (mata atlântica) na costa leste do Brasil. Revista Árvore, v. 27, n. 2, p. 159-170, 2003.
ALMEIDA, A.C. et al. Growth and water balance of Eucalyptus grandis hybrid plantations in Brazil during a rotation for pulp production. Forest Ecology and Management, v. 251, n. 1-2, p. 10-21, 2007.

BLUN, A. Drought resistance, water-use efficiency, and yield potential - are they compatible, dissonant, or mutually exclusive. Australian Journal of Agricultural Research, v. 56, n. 11, p. 1159-1168, 2005.

CALDATO, S.L.; SCHUMACHER, M.V. O uso de água pelas plantações florestais - uma revisão. Ciência Florestal, v. 23, n. 3, p. 507516, 2013.

CARNEIRO, R.L.C et al. Consumo de água em plantios de eucalipto: parte 1 determinação da condutância estomática em tratamentos irrigado e não irrigado. Revista Árvore, v. 32, n. 1, p. 110, 2008.

CHAGAS, G.F.B. et al. Impactos da redução da pluviometria na biomassa aérea da Floresta Amazônica. Revista Brasileira de Engenharia Agrícola e Ambiental, v. 16, n. 1, p. 72-79, 2012.

CHAVES, J.H. et al. Seleção precoce de clones de eucalipto para ambientes com disponibilidade diferenciada de água no solo: relações hídricas de plantas em tubetes. Revista Árvore, v. 28, n. 3, p. 333-341, 2004.

CHAVES, M.M.; FLEXAS, J.; PINHEIRO C. Photosynthesis under drought and salt stress: regulation mechanisms from whole plant to cell. Annals of Botany, v. 103, n. 4, p. 551-560, 2009.

FERRAZ, T.M. Ecofisiologia de clones de eucalipto submetidos à restrição hídrica em condições de campo. 2012. 138 f. Tese (Doutorado em Produção Vegetal) Universidade Estadual do Norte Fluminense Darcy Ribeiro, Campos dos Goytacazes. 2012. 
GARAU, P.M. et al. Water stress tolerance in Eucalyptus globulus Labil subsp. Maidenii saplings induced by water restriction imposed by weeds. Forest ecology and management, v. 255, n. 7, p. 2811-2819, 2008.

HUBBARD, R.M. et al. Effects of irrigation on water use and water use efficiency in two fast growing Eucalyptus plantations. Forest Ecology and management, v. 259, n. 9, p. 1714-1721, 2010 .

IBÁ, Indústria Brasileira de árvores: ano base 2016/IBÁ. Brasília/DF, 2016. 100 p.

LACLAU, P.B. et al. Potassium fertilization increases water-use efficiency for stem biomass production without affecting intrinsic water-use efficiency in Eucalyptus grandis plantations. Forest Ecology and Management, v. 364, p. 77-89, 2016.

LIMA, K. B. Clones de Eucalyptus sp. submetidos a estresse hídrico em dois tipos de solo. 2015. 68 f. Dissertação (Mestrado em Agronomia) - Faculdade de Ciências Agronômicas da UNESP - Campus de Botucatu. 2015.

MARTINS, F.B. et al. Deficiência hídrica no solo e seu efeito sobre transpiração, crescimento e desenvolvimento de mudas de duas espécies de eucalipto. Revista Brasileira de Ciência do Solo, v. 32, n. 3, p. 1297-1306, 2008.

MASEDA, P.H.; FERNÁNDEZ, R.J. Growth potential limits drought morphological plasticity in seedlings from six Eucalyptus provenances. Tree physiology, v. 36, n. 2, p.243-251, 2016.

MATOS, F.S. Eucalyptus urocan drought tolerance mechanisms. African Journal of Agricultural Research, v. 11, n. 18, p. 16171622, 2016.

MITCHELL, P.J.; O'GRADY, A.P. Adaptation of Leaf Water Relations to Climatic and Habitat
Water Availability. Forests, v. 6, p. 2281-2295, 2015.

MORONI, M.T; WORLEDGE, D; BEADLE, C.L. Root distribution of Eucalyptus nitens and E. globulus in irrigated and droughted soil. Forest Ecology and Management, v. 177, n. 1-3, p. 399-407, 2003.

MUGUNGA, C.P. et al. Water use by short rotation Eucalyptus woodlots in southern Rwanda. Agroforestry Systems, v. 89, n. 6, p. 1119-1139, 2015.

O'GRADY, A.P.; WORLEDGEB, D. BATTAGLIAB, M. Constraints on transpiration of Eucalyptus globulus in southern Tasmania, Australia. Agricultural and Forest Meteorology, v. 148, n. 3, p. 453-465, 2008.

OTTO, M.S.G. et al. Fotossíntese, condutância estomática e produtividade de clones de Eucalyptus sob diferentes condições edafoclimáticas. Revista Árvore, v. 37, n. 3, p. 431-439, 2013.

OTTO, M.S.G et al. Dominant clonal Eucalyptus grandis $\mathrm{x}$ urophylla trees use water more efficiently. Forest Ecology and Management. v. 328, p. 117-121, 2014.

PEREIRA, M.R.R. et al. Comportamento fisiológico e morfológico de clones de Eucalyptus urograndis submetidos a diferentes níveis de água no solo. Irriga, v. 11, n. 4, p. 518531, 2006.

PITA, P; PARDOS, J.A. Growth, leaf morphology, water use and tissue water relations of Eucalyptus globulus clones in response to water deficit. Forest ecology and management, v. 21, n. 9, p. 599-607, 2001.

ROBERTS, S. et al. Predicting the water use of Eucalyptus nitens plantation sites in Tasmania from inventory data, and incorporation of water use into a forest estate model. Forest Ecology and Management, v. 343, p. 110-122, 2015. 
RYAN, M.G. et al. Factors controlling Eucalyptus productivity: How water availability and stand structure alter production and carbon allocation. Forest Ecology and Management, v. 259, n. 9, p. 1695-1703, 2010.

SANTOS, R.F.; CARLESSO, R. Déficit hídrico e os processos morfológico e fisiológico das plantas. Revista Brasileira de Engenharia Agrícola e Ambiental, v. 2, n. 3, p. 287-294, 1998.

SILVA, F.C. et al. Responses to water stress in two Eucalyptus globulus clones differing in drought tolerance. Tree Physiology, v. 24, n. 10, p.1165-1172, 2004a.

SILVA, W. et al. Índice de consumo e eficiência do uso da água em eucalipto, submetido a diferentes teores de água em convivência com braquiária. Floresta, v. 34, n. 3, p. 325-335, 2004b.

STAPE, J.L. et al. The Brazil Eucalyptus Potential Productivity Project: Influence of water, nutrients and stand uniformity on wood production. Forest Ecology and Management, v. 259, n. 9, p. 1684-1694, 2010.

TAIZ, L.; ZEIGER, E. Fisiologia vegetal. 5 ed. Porto Alegre: Artmed, 2014. 918 p.

TATAGIBA, S.D. et al. Comportamento fisiológico de dois clones de Eucalyptus na época seca e chuvosa. Cerne, v. 13, n. 2, p. 149159, 2007a.

TATAGIBA, S.D. et al. Variabilidade diurna e sazonal das trocas gasosas e do potencial de água das folhas de clones de Eucalyptus. Engenharia na Agricultura, v. 16, n. 2, p. 225-237, 2007 b.

TATAGIBA, S.D.; PEZZOPANE, J.E.M; REIS, E.F. Relações hídricas e trocas gasosas na seleção precoce de clones de eucalipto para ambientes com diferenciada disponibilidade de água no solo. Floresta, v. 38, n. 2, p. 387-400,
2008.

TATAGIBA, S. D.; PEZZOPANE, J. E. M.; REIS, E. F.; PENCHEL, R. M. Desempenho de clones de eucalipto em resposta a disponibilidade de água no substrato. Engenharia na Agricultura, v. 17, n. 3, p. 179189, 2009.

TONELLO, K.C.; TEIXEIRA FILHO, J. Transpiração e condutância estomática de Eucalyptus sp em resposta à radiação global e diferentes condições hídricas. Irriga, v. 18, n. 4, p. 607-623, 2013.

VALDÉS, A.E. et al. Drought tolerance acquisition in Eucalyptus globulus (Labill.): A research on plant morphology, physiology and proteomics. Journal of proteomics, v. 79, p. 263-276, 2013.

VANCLAY, J.K. Managing water use from forest plantations. Forest Ecology and Management, v. 257, n. 2, p. 385-389, 2009.

VELLINNI, A.L.T.T. et al. Respostas fisiológicas de diferentes clones de eucalipto sob diferentes regimes de irrigação. Revista Árvore, v. 32, n. 4, p. 651-663, 2008.

WHITE, D. A. Managing for water-use efficient wood production in Eucalyptus globulus plantations. Forest Ecology and Management, v. 331 p. $272-280,2014$.

ZHU, L.W. Stomatal and hydraulic conductance and water use in a eucalypt plantation in Guangxi, southern China. Agricultural and Forest Meteorology, v. 202, p. 61-68, 2015. 